\title{
A preliminary study on applying holistic health care model on medical education behavioral intention: a theoretical perspective of planned behavior
}

Liang-Miin Tsai ${ }^{1}$ and Yu-Hua Yan ${ }^{1,2^{*}}$ (D)

\begin{abstract}
Background: This study aimed to apply the theory of planned behavior to identify the medical education behavioral intention of holistic healthcare on teachers and students who influence the medical and healthcare profession, as a revised future direction for hospitals to continue to implement holistic healthcare.

Methods: This cross-sectional study was performed from April to May 2020. A questionnaire survey was conducted with the clinical teachers and students of the medical and healthcare profession in an individual Taiwan hospital as study subjects, based on judgmental sampling, and the study tool was a structured questionnaire.

Results: A total of 360 valid samples were collected, 105 clinical teachers (29.2\%) and 255 students (70.8\%). Demographic variables were significantly different between clinical teachers (mean $=3.91$ ) and students ( mean $=$ 3.73) $(p=0.023)$. Post hoc analysis regarding work experience found that those with work experience $<2$ years (mean $=3.94)$ had higher results than those with $6-10$ years (mean $=3.61)(p=0.019)$. The results of multiple regression analysis indicate that the factors affecting medical education behavioral intention are subjective norm $(\mathrm{t}=3.571, p<0.001)$ and perceived behavioral control $(\mathrm{t}=11.870, p<0.001)$.

Conclusions: With respect to medical education behavioral intention, clinical teachers and students are affected by the subjective norm and perceived behavioral control. It is recommended that, in the curriculum of holistic medical education, designing holistic medical education teaching templates and check forms can encourage clinical teachers to re-examine their beliefs in teaching, learning, and knowledge. The results of this study allow the advocator to consider from a broader view making policies of and promoting the platform of holistic healthcare on medical education. It is recommended that future researchers conduct research, investigation, and analysis on other stakeholders.
\end{abstract}

Keywords: Holistic health care, Medical education, Behavioral intention, Postgraduate general clinic medicine training

\footnotetext{
* Correspondence: 2d0003@mail.tmh.org.tw

'Superintendent Office, Tainan Municipal Hospital (Managed by Show

Chwan Medical Care Corporation), No. 670, Chung Te Road, Tainan City 701,

Taiwan

${ }^{2}$ Department of Hospital and Health Care Administration, Chia Nan University

of Pharmacy and Science, No.60, Sec. 1, Erren Rd., Rende Dist, Tainan City

71710, Taiwan
}

(c) The Author(s). 2021 Open Access This article is licensed under a Creative Commons Attribution 4.0 International License, which permits use, sharing, adaptation, distribution and reproduction in any medium or format, as long as you give appropriate credit to the original author(s) and the source, provide a link to the Creative Commons licence, and indicate if changes were made. The images or other third party material in this article are included in the article's Creative Commons licence, unless indicated otherwise in a credit line to the material. If material is not included in the article's Creative Commons licence and your intended use is not permitted by statutory regulation or exceeds the permitted use, you will need to obtain permission directly from the copyright holder. To view a copy of this licence, visit http://creativecommons.org/licenses/by/4.0/. The Creative Commons Public Domain Dedication waiver (http://creativecommons.org/publicdomain/zero/1.0/) applies to the data made available in this article, unless otherwise stated in a credit line to the data. 


\section{Background}

Holistic healthcare is a medical care model that was proposed by the Ministry of Health and Welfare (Taiwan) in 2005 when it was promoting the "Holistic Health Care Plan." Not only does it emphasize the need to provide correct and effective prevention methods and patientcentered medical care, it also stresses the need for correct and dignified rehabilitation and support during illness [1]. With the evolution of human civilization, people have been constantly seeking progress, as has medicine. Therefore, the concept of holistic medicine has been gradually gaining attention in the medical field $[2,3]$. Recently, after many reflections and reviews, medical circles at home and abroad have returned to a holistic view, emphasizing that complete medical care must cover a person's physical, mental, and spiritual needs and that we must attach importance to his/her social adaptation. However, to implement holistic medical education, attention must be paid to every stage, from basic education of medical staff to continued education after graduation, from acute medical care to chronic longterm care, and from medical centers to community primary medical care $[4,5]$.

In addition to understanding the patient's physical pain during the training process of a medical care team, psychological pressure, family burden, and re-adaptation of social roles all require education and training [6]. Providing holistic healthcare by a cross-disciplinary team can help resolve patients' fears of disease and treatment [7] and deliver more complete holistic healthcare. Concurrently, it also allows professionals to continue to grow at work and improve the quality of medical care [8]. The ultimate goal is to promote patient's recovery and return to the normal quality of life $[9,10]$.

The theory of planned behavior (TPB) is the most extensive and influential theory in human behavioral research [11-14]. The theory is derived from the theory of reasoned action proposed by Fishbein and Ajzen [15]. Ajzen [16] amended the missing parts of the theory of reasoned action and increased its explanatory power. TPB comprises factors of "attitude (AT)," "subjective norm (SN)," and "perceived behavior control (PBC)" and in the end "behavioral intention (BI)" $[16,17]$. Moreover, "attitude" means that an individual has a positive or negative evaluation of a specific behavior. "Subjective norms" refer to the individual feeling of social pressure from other individuals or groups. "Perceived behavior control" refers to the degree of simplicity or difficulty that an individual perceives when performing a specific behavior. "Behavioral intention" is the result guided by the decision process of behavior choice [18].

The TPB has been continuously verified by researchers in different fields over the years and widely used in various research topics [19]. In the field of medical care, these topics include disease treatment behavior (insulin injection intention) [20]; intention of physicians and non-physicians to protect the privacy of electronic medical records [21]; behavioral intention of licensed pharmacists in hospitals to avoid erroneous dispensing [22]; attitude, subjective norm, and PBC influencing his/her intention for oral hygiene care [23]; and a hospital manager's attitude and PBC influencing the intention of empirical management [24].

Previously, many researches on holistic medical education and training at home and abroad were mostly focused on research on medical knowledge and teaching techniques [25-27]. There is no empirical research on how the promotion of holistic medical education is affected by those factors affecting their behavioral intentions. This study still awaits further in-depth research by scholars. The main problem with holistic medical education and training is that each hospital still has its own exploration and lacks complete effectiveness evaluation based on the view that holistic medical education and training plays a greatly important role in the development of physicians or medical staff and that it can provide patients with more complete holistic medical care.

This study primarily aimed to apply the TPB to identify the factors influencing the behavioral intention of medical and healthcare clinical teachers and students toward promoting holistic healthcare in hospitals. This strategy is not featured in published medical educational literature, although promising research is emerging from other disciplines. Under the concept of general medicine, we can complete the learning goals of medical education and training of holistic healthcare and combine the TPB, as a revised future direction for hospitals to continue to implement holistic healthcare. Concurrently, it can also make up for the gaps in previous studies.

\section{Methods \\ Design, participants, and procedures}

The survey period of this study was from April 1, 2020 to May 31, 2020. The subjects of the study were clinical teachers and students in the medical and healthcare profession from a medical care corporation hospital in Southern Taiwan. This cross-sectional study was conducted using judgmental sampling, and the study tool was a structured questionnaire. The clinical teachers and students had a free will to decide whether they were willing to participate in this study. According to the hospital statistics, there were approximately 419 clinical teachers and students in the medical and healthcare profession, and the questionnaires were distributed to them.

Distribution and collection of questionnaires were conducted by the researchers. Teachers and students who agreed to participate in the medical and healthcare professions of this study were included in the survey, 
and those who do not meet the acceptance criteria of this study were excluded. All participants were informed about the study's aim, and their consent for participation was obtained at the beginning of the study. The participants filled in the basic information and various questionnaire assessments, and the researcher tracked the participant's questionnaire fill-in situation and checked whether the interviewee's record was complete when receiving the information to reduce the missing value of the data.

\section{Sample size}

According to Dillman [28], the sample size can be estimated using the following formula: $N_{S A M P L E}$ $=\frac{\left(N_{P}\right)(p)(1-p)}{\left(N_{P}-1\right)(E / C)^{2}+(p)(1-p .)}$

$N_{S A M P L E}$ is the sample size; $N_{P}$ is the population size; $E$ is the tolerance error; $C$ is the $\mathrm{Z}$ value (1.96) of $95 \%$ confidence interval; and $p, 1-p$ is the population variance. Under consideration of normal distribution and fitting expected characteristic, the maximum population variance was $50 \%$. According to the formula above, the minimum standard of sample size was 201 . The sample size was 360 . The result (360) was more than the minimum standard (201). Hence, the number of sample was acceptable in this study.

\section{Study tools}

The study tool was a structured questionnaire. We formulated the questionnaire scale with references to relevant literature, current operations, and expert interviews on designing questions, using the scoring method of the five-point Likert scale. The participants were instructed to respond on a five-point Likert scale in numerical values: 5 (strongly agree), 4 (agree), 3 (neutral), 2 (disagree), and 1 (strongly disagree), for all statements. Questionnaires used in this study included the following: (1) eight questions on basic demographic and sample characteristics data (sex, age, education level, marital status, practice discipline or department, clinical teacher qualification, current job title, and current years of services) and (2) 26 questions on participation behavior and medical education behavioral intention (attitude, subjective norm, $\mathrm{PBC}$, and medical education behavioral intention), with a total of 34 questions.

Regarding the compilation of measurement question group based on the TPB construct, first, the measurement method recommended by the theory was used as basis before relevant domestic and foreign literature was consulted. Relevant question groups were drafted on the researcher's own medical work experience. Relevant opinions and questions were collected through interviews with clinical teachers and students. Following the compilation of the first draft of the questionnaire, the opinions of three experts were sought. According to the recommendations of these experts, questions were added, deleted, and revised to strengthen the content validity.

\section{Validity and reliability analysis}

We used Cronbach's $\alpha$ analysis to analyze the internal consistency of the measurement variables of each dimension to understand the reliability of the measurement dimension. Generally speaking, Cronbach's $\alpha$ value $>0.9$ represented a high reliability value. The analysis showed the following results: Cronbach's $\alpha$ values in "attitude," 0.957; "subjective norm," 0.950; "perceived behavior control," 0.949; and "medical education behavioral intention," 0.946. Cronbach's $\alpha$ value for each scale and the overall questionnaire was 0.973 , all of which were $>0.9$, indicating that the questionnaire in this study had very good reliability.

Experts were invited to conduct a validity analysis, and the expert consensus calculated the content validity index (CVI) as 0.98 , which is extremely efficient. The CVI value of each item on the four scales ranged from 0.80 to 1 , indicating that the questionnaire in this study had very good validity.

\section{Ethics approval and consent to participate}

This study adheres to the guidelines of the Declaration of Helsinki. This study was granted an ethics waiver by the Institutional Review Board at Show Chwan Memorial Hospital (IRB1090203). According to the same committee, formal written informed consent was not required.

Similarly, the study was deemed as "not involving human subjects research" by the Institutional Review Board at Show Chwan Memorial Hospital Human Subjects Committee and exempted from human subjects' oversight. The first author invited all participants by email or telephone, emphasizing that participation was voluntary and anonymous. All participants provided oral consent.

\section{Statistical analysis}

After the valid questionnaire data were decoded and input, statistical analysis was conducted with the SPSS 22.0 statistical package as the tool. All data were checked and screened with descriptive statistics, and errors were eliminated before statistical analysis was performed.

\section{Results}

In this study, 419 questionnaires were sent to the clinical teachers and students in the medical and healthcare profession, and a total of 364 questionnaires were retrieved. After four invalid questionnaires were eliminated, 360 valid questionnaires were obtained, with a recovery rate 
of $85.9 \%$. Relevant basic data analysis is shown in Table 1. Among the 360 questionnaires retrieved, 257 were women $(71.4 \%)$. There were 105 clinical teachers (29.2\%) and 255 students (70.8\%). Most of them were aged 41-50 years (34.2\%), had university degrees (86.1\%), and were unmarried (50.6\%). For those with working experience of $>10$ years $(46.7 \%), 100$ were in the medical departments $(27.8 \%)$ and 260 were in the healthcare departments $(72.2 \%)$.

The scale scores of the four dimensions of this study were as follows: Attitude average was $4.21 \pm 0.62$ points, subjective norm average was $4.04 \pm 0.68$ points, perceived behavioral control average was $3.65 \pm 0.73$ points, and behavior intention average was $3.78 \pm 0.66$ points. In terms of attitude, the scale of "holistic medical education is valuable" scored the highest ( 4.3 points), and the scale of subjective norm was "the hospital will arrange teaching holistic medical education courses," with 4.09 the

Table 1 Characteristics of the study population $(n=360)$

\begin{tabular}{|c|c|c|}
\hline Item & $\mathrm{N}$ & $\%$ \\
\hline \multicolumn{3}{|l|}{ Sex } \\
\hline Female & 257 & 71.4 \\
\hline Male & 103 & 28.6 \\
\hline \multicolumn{3}{|l|}{ PGY } \\
\hline Clinical teachers & 105 & 29.2 \\
\hline Trainee & 255 & 70.8 \\
\hline \multicolumn{3}{|l|}{ Job title } \\
\hline Manager & 100 & 27.8 \\
\hline Staff & 260 & 72.2 \\
\hline \multicolumn{3}{|l|}{ Age (years) Mean: 38.9} \\
\hline$<30$ & 96 & 26.9 \\
\hline $31-40$ & 94 & 26.1 \\
\hline $41-50$ & 123 & 34.2 \\
\hline$>50$ & 47 & 13.1 \\
\hline \multicolumn{3}{|l|}{ Education level } \\
\hline Bachelor's degree & 310 & 86.1 \\
\hline Master's degree & 50 & 13.9 \\
\hline \multicolumn{3}{|l|}{ Marital status } \\
\hline Single & 182 & 50.6 \\
\hline Married & 178 & 49.4 \\
\hline \multicolumn{3}{|l|}{ Job tenure (year) } \\
\hline$\leq 2$ & 102 & 28.3 \\
\hline $3-5$ & 48 & 13.3 \\
\hline $6-10$ & 42 & 11.7 \\
\hline$>10$ & 168 & 46.7 \\
\hline \multicolumn{3}{|l|}{ Category } \\
\hline Medical personnel & 260 & 72.2 \\
\hline Physicians & 100 & 27.8 \\
\hline
\end{tabular}

highest. Perceived behavioral control had the highest score of 3.77 for "I encounter problems in teaching (or learning) holistic medical education courses, and it is easy to get support from others." Behavior intention had the highest score of 3.9 for "I am motivated to study holistic medical education courses".

To understand the relationship between the study variables, this study used the Pearson correlation matrix to determine the degree of correlation between various dimensions. The results of the study are shown in Table 2 . The correlation coefficient $r$ was 0.843 between attitude and subjective norm, 0.599 between attitude and PBC, and 0.591 between attitude and medical education behavioral intention. The degree of correlation between the two groups reached a positive correlation of high significance $(p<0.001)$.

\section{Differences in medical education behavioral intentions among different demographic backgrounds and sample characteristics}

In this study, t-test and single factor variance analyses were used to determine the differences in medical education behavioral intentions among different demographic backgrounds and sample characteristics (Table 3). The results demonstrated that there was a significant difference between clinical teachers and students $(p<0.05)$ and the variable "years of working" also showed a statistically significant difference $(p<0.05)$. After Scheffé post hoc analysis was applied, it was found that those with a working experience of $<2$ years had higher scores than those with a working experience of $6-10$ years $(p<0.05)$.

\section{Distribution of attitude, subjective norm, PBC, and medical education behavioral intention}

Once the correlation among the various dimensions was understood through correlation analysis, this study used regression analysis to explore the degree of influence of attitude, subjective norm, and PBC on medical education behavioral intention. The results of the multiple regression analysis shown in Table 4 demonstrated that the overall F-test value was 191.24 $(p<0.001)$, indicating the significance of using attitude, subjective norm, and PBC as predictive variables to predict the overall and medical education behavioral intentions. These variables explain

Table 2 Correlation (Pearson correlation analysis)

\begin{tabular}{lllll}
\hline Item & AT & SN & PBC & BI \\
\hline 1. Attitude & 1 & & & \\
2. Subjective norm & $.843^{* * *}$ & 1 & & \\
3. Perceived behavioral control & $.599^{* * *}$ & $.708^{* * *}$ & 1 & \\
4. Behavior intention & $.591^{* * *}$ & $.682^{* * *}$ & $.758^{* * *}$ & 1 \\
${ }^{* * *} p<.001$ & & &
\end{tabular}


Table 3 Differences in medical education behavioral intentions among different demographic backgrounds and sample characteristics $(n=360)$

\begin{tabular}{|c|c|c|c|c|c|}
\hline Item & $\mathrm{N}$ & Mean & SD & $P$-value & Scheffé \\
\hline Sex & & & & .999 & \\
\hline Female & 257 & 3.78 & .61 & & \\
\hline Male & 103 & 3.78 & .76 & & \\
\hline PGY & & & & $.023^{* *}$ & \\
\hline Clinical teachers & 105 & 3.91 & .67 & & \\
\hline Trainee & 255 & 3.73 & .65 & & \\
\hline Job title & & & & .890 & \\
\hline Manager & 100 & 3.78 & .65 & & \\
\hline Staff & 260 & 3.79 & 68 & & \\
\hline Age (years) Mean: 38.9 & & & & .051 & \\
\hline$<30$ & 96 & 3.91 & .59 & & \\
\hline $31-40$ & 94 & 3.69 & .69 & & \\
\hline $41-50$ & 123 & 3.72 & .62 & & \\
\hline$>50$ & 47 & 3.87 & .75 & & \\
\hline Education level & & & & .362 & \\
\hline Bachelor's degree & 310 & 3.77 & .65 & & \\
\hline Master's degree & 50 & 3.86 & .69 & & \\
\hline Marital status & & & & .187 & \\
\hline Single & 182 & 3.83 & 62 & & \\
\hline Married & 178 & 3.74 & .70 & & \\
\hline Job tenure (year) & & & & $.019^{* *}$ & $(1)>(3)$ \\
\hline$\leq 2(1)$ & 102 & 3.94 & .68 & & \\
\hline $3-5(2)$ & 48 & 3.70 & .58 & & \\
\hline $6-10(3)$ & 42 & 3.61 & .70 & & \\
\hline$>10(4)$ & 168 & 3.75 & .64 & & \\
\hline Category & & & & .969 & \\
\hline Medical personnel & 260 & 3.78 & .77 & & \\
\hline Physicians & 100 & 3.78 & .61 & & \\
\hline
\end{tabular}

the variation $(61.40 \%)$ in the overall medical education behavioral intention and significance level. Among the influences of various predictive variables on the overall medical education behavioral intention, PBC $(\beta=0.552$, $p<0.001$ ) had the greatest influence, followed by subjective norm $(\beta=0.247, p<0.001)$, whereas attitude $(\beta=0.052, p=0.392)$ did not reach a significance level. Moreover, the variance inflation factor of each predictive variable was $<10$, which indicated that there was no multicollinearity problem among the three predictive variables.

\section{Discussion}

To implement holistic healthcare, it is necessary to adopt a sound medical education system, appropriate learning fields, and dedication of clinical teachers to holistic medical education. This study is based on the TPB by Ajzen [17], which, in a broad sense, is supported by experience. Through behavioral attitude, subjective norm, and PBC, the intentions of various types of behaviors can be predicted. Similar to previous studies, this study shows that, in physicians and medical staff, there is high correlation between the influences of "subjective norm" and "perceived behavior control" on medical education behavioral intention. Thus, if a hospital has a system that requires clinical teachers to guide students to understand the needs (physical, psychological, spiritual, and social) of patients, their medical education behavioral intention could be higher. However, this result has not been previously described. The existence of institutional norms is closely related to the development of holistic medicine, and how to promote the willingness of "people" to implement "systems" will be a challenge.

Moreover, the more a teacher thinks that he/she is in possession of professional knowledge, teaching resources, and environmental opportunities, the more likely that he/she is self-confident, which affects perceived behavior, leading to heightened intention to implement holistic medical education. The study of Pong [29] also confirmed critical factors for the successful implementation of holistic medical education through experiential learning. Therefore, in the future, if we were to increase the behavioral intention of a teacher to implement holistic medical education, we should start by controlling this aspect of perceived behavior.

Furthermore, in the past, researchers believed that "behavioral intention" was determined by three factors, namely, "attitude," "subjective norm," and "perceived behavior control" [16, 17]; however, according to the

Table 4 Prediction and explanatory power of each predictive variable on the overall behavioral intention

\begin{tabular}{|c|c|c|c|c|c|}
\hline \multirow[t]{2}{*}{ Item } & \multirow{2}{*}{$\begin{array}{l}\text { Standardized } \\
\text { coefficient } \beta\end{array}$} & \multirow[t]{2}{*}{$t$ value } & \multirow[t]{2}{*}{$P$-value } & \multicolumn{2}{|c|}{ Collinearity diagnostics } \\
\hline & & & & Tolerance & VIF \\
\hline Constant & & 5.251 & $<.001$ & & \\
\hline Attitude & .052 & .857 & .392 & .290 & 3.448 \\
\hline Subjective norm & .247 & 3.574 & $<.001$ & .225 & 4.439 \\
\hline Perceived behavioral control & .552 & 11.870 & $<.001$ & .498 & 2.007 \\
\hline$R^{2}=0.617$ & Adj $R^{2}=0.614$ & $F=191.24$ & $P<0.001$ & & \\
\hline
\end{tabular}


results of this study, "attitude" does not have a significant influence on "behavioral intention," the possible reason being that clinical teachers have yet to undergo positive or negative evaluations on the implementation of holistic medical education. This outcome is contrary to that of Guo et al. [24], who found that education positively moderated the relationship between attitudes and intention to use evidence-based management. Holistic medical care is a medical care model, whereby the patient's medical care is delivered by cross-disciplinary professional medical service providers, and exclusive medical plans are tailored made according to the patient's life pattern, mental state, and various real-life needs. Therefore, if clinical teachers and students are encouraged to make positive evaluations of holistic medical education through various teaching mechanisms, the hospital's satisfactory level with overall promotion of holistic medical education will increase.

Finally, there is a significant difference between postgraduate general clinic medicine training (PGY) clinical teachers or Trainee and work experience in medical education behavioral intention. One possible reason for this is that the hospital has only recently introduced holistic medical education and training. Clinical teachers may be busy at work while responsible for teaching, and the workload of clinical teachers and students is different. As a result, students have different behavioral intentions for holistic medical education. Ottenhoff-de Jonge et al. [30] showed that the educational beliefs of medical educators influence their teaching practices. It is possible that, if the hospital can appropriately adjust and improve the workload of clinical teachers, it will help the implementation of holistic medical education and potentially help the development of clinical teachers' work.

\section{Implications for teaching and future research}

Current research results show that subjective norms and perceptual behavior control have an impact on medical education behavior. Therefore, in the curriculum of holistic medical education, designing holistic medical education teaching templates and check forms can help them realize their beliefs and can encourage clinical teachers to re-examine their beliefs in teaching, learning, and knowledge. Reflecting on how to determine which holistic medical knowledge is relevant to learning, creating a positive learning atmosphere, and cultivating students' internal motivation are critical to the quality of our education. The healthcare professionals of the future are of major importance for the quality of our education of future healthcare professionals.

Further research is needed to investigate the extent to which the beliefs of the hospital manager can change and develop toward holistic healthcare model- centeredness. For such a study, the presented framework can provide a useful instrument.

\section{Additional limitations}

This study only focuses on the clinical teachers and students in the individual hospital as study subjects, and the conclusion may not be inferred to other hospitals; hence, there is a rather limited extrapolability. It is suggested that, in future studies, samples should be expanded to hospitals of various levels to improve the extrapolability of the study results. Moreover, the reasons for the variables (e.g., attitude) that have not received empirical support in this study still require further qualitative studies, such as field interviews and secondary data collection. Finally, as the subjects of this study are clinical teachers and students, it is recommended that future researchers conduct research, investigation, and analysis on other stakeholders (e.g., hospital operators).

\section{Conclusions}

Based on the results of this study, it is recommended that hospitals apply the following methods when implementing holistic medical education: 1 . cross-disciplinary discussions and meetings in relation to holistic medical education, in which students (trainees) may practice and participate in interdisciplinary holistic healthcare; 2 . cross-disciplinary team learning to create a cooperative relationship of providing care together; 3 . learning platform that provides clinical teachers and students with more holistic medical education and training; and 4. the establishment of system standards can make the implementation of holistic medical education more practical.

\section{Abbreviations}

PGY: Postgraduate general clinic medicine training; CVI: Content validity index; TPB: The theory of planned behavior; AT: Attitude; SN: Subjective norm; PBC: Perceived behavior control; BI: Behavioral intention

\section{Acknowledgements \\ We are grateful for Tainan Municipal Hospital (Managed by Show Chwan Medical Care Corporation) for providing the data and was supported. The views expressed in this article are those of the authors and do not represent views of the funding agency.}

\section{Authors' contributions}

The authors confirm contribution to the paper as follows: Yan conceived and designed the study, performed the statistical analyses, was in charge of recruiting study participants, helped design the study, collected information, and interpreted the data. Tsai monitored the research and assist in editing and correcting the paper. All authors have read and approved the final paper.

\section{Funding}

Tainan Municipal Hospital (Managed by Show Chwan Medical Care Corporation), Grant/Award: RA20005

Availability of data and materials

Data cannot be made publically available owing to the fact that the privacy of individual participants cannot be compromised. However, the dataset is available from the corresponding author on reasonable request. 


\section{Declarations}

\section{Ethics approval and consent to participate}

This study adheres to the guidelines of the Declaration of Helsinki. This study was granted an ethics waiver by the Institutional Review Board at Show Chwan Memorial Hospital (IRB1090203). According to the same committee, formal written informed consent was not required. Similarly, the study was deemed as "not involving human subjects research" by the Institutional Review Board at Show Chwan Memorial Hospital Human Subjects Committee and exempted from human subjects' oversight. The first author invited all participants by email or telephone, emphasizing that participation was voluntary and anonymous. All participants provided oral consent."

\section{Consent for publication}

Not applicable.

\section{Competing interests}

The authors declare that they have no competing interests.

Received: 25 February 2021 Accepted: 18 May 2021

Published online: 28 May 2021

\section{References}

1. Hou SM. Promote the whole-person care plan and improve the doctor training system. Taiwan Med Assoc. 2006;49:3-5 [in Chinese].

2. Curtin LL. This I believe... about the care of human beings. Nurs Manag. 1996;27:5-8.

3. Eriksson I, Lindblad M, Möller U, Gillsjö C. Holistic health care: Patients' experiences of health care provided by an advanced practice nurse. Int J Nurs Pract. 2018;24(1):e12603. https://doi.org/10.1111/ijn.12603.

4. Lin HJ. My opinions on holistic care medical education. J Healthc Qual. 2017;11:9-13 [in Chinese].

5. Chen CC, Lin YL, Lin SC, Yu CB, Lin JP. Promotion of holistic care medical education. J Healthc Qual. 2018;12:35-8 [in Chinese].

6. Lin MN. Holistic health pioneer do. Tzu Chi Nurs J. 2019;18:12-3 [in Chinese].

7. Housten T, Bryan L, Kelemen A. Holistic care for patients with pulmonary hypertension. Adv Pulm Hypertens. 2018;17(1):32-3. https://doi.org/10.21 693/1933-088X-17.1.32.

8. Huang YT, Chen CH, Tang MH, Chiu WY, Tsao YC, Chang YC, et al. Workplace education: a case report of using interprofessional collaborative patiented care in a child development evaluation team meeting. Bull Med Educ Taichung Veterans General Hosp. 2016;19:3-9 [in Chinese].

9. Tu MS, Chang HT, Chen RY, Huang FY. Case-based clinical teaching of holistic care: an application to patient safety, medical ethics and laws, and evidence-based-medicine. J Med Educ. 2005;9:282-9 [in Chinese].

10. Jan CF, Chen CY. Family physician person-centered care system. J Med Educ. 2003;7:207-9 [in Chinese].

11. Jafarkarimi $H$, Saadatdoost $R$, Sim ATH, Hee JM. Behavioral intention in social networking sites ethical dilemmas: an extended model based on theory of planned behavior. Comput Hum Behav. 2016;62:545-61. https://doi.org/10.1 016/j.chb.2016.04.024.

12. Mancha RM, Yoder CY. Cultural antecedents of green behavioral intent: an environmental theory of planned behavior. J Environ Psychol. 2015:43:14554. https://doi.org/10.1016/j.jenvp.2015.06.005.

13. Yazdanpanah M, Forouzani M. Application of the theory of planned behaviour to predict Iranian students' intention to purchase organic food. J Clean Prod. 2015;107:342-52. https://doi.org/10.1016/j.jclepro.2015.02.071.

14. Zhou H, Romero SB, Qin X. Understanding why consumers engage in electronic word-of-mouth communication: perspectives from theory of planned behavior and justice theory. Electron Commer Res Appl. 2015;14: 616-30

15. Fishbein M, Ajzen I. Belief, attitude, intention, and behavior: an introduction to theory and research. Reading: Addison-Wesley; 1975.

16. Ajzen I. From intentions to actions: a theory of planned behavior. In: Kuhl J, Beckman J, editors. Action-control: from cognition to behavior. Springer: Heidelberg; 1985. p. 11-39.

17. Ajzen I. The theory of planned behavior. Organ Behav Hum Decis Process. 1991;50(2):179-211. https://doi.org/10.1016/0749-5978(91)90020-T.

18. Ajzen I. Attitude structure and behavior. In: Pratkanis AR, Breckler SJ, Greenwald AG, editors. The third Ohio State University Vol. on attitudes and persuasion. Attitude structure and function. New Jersey: Lawrence Erlbaum Associates, Inc; 1989. p. 241-74.

19. Rivis A, Sheeran P, Armitage CJ. Expanding the affective and normative components of the theory of planned behavior: a meta-analysis of anticipated affect and moral norms. J Appl Soc Psychol. 2009;39(12):29853019. https://doi.org/10.1111/j.1559-1816.2009.00558.x.

20. Tiunn IT, Hsiao YC. Application of theory of planned behavior for the prediction of insulin injection intention among patients with type 2 diabetes. Taiwan J Fam Med. 2016;26:88-99 [in Chinese].

21. Kuo KM, Ma CC, Wu HS. A comparative study of the intention to protect the privacy of the electronic medical record by physicians and non-physician staff. Taiwan J Public Health. 2014;33:162-73 [in Chinese].

22. Chian MS, Pan FC, Chen CL. A study on the hospital pharmacists' intentions of avoiding dispensing errors. Pao-Chien J Healthc Manag. 2012;10:5-22 [in Chinese].

23. Ab Malik N, Mohamad Yatim S, Lam OL, Jin L, McGrath C. Factors influencing the provision of oral hygiene care following stroke: an application of the theory of planned behaviour. Disabil Rehabil. 2018;40(8): 889-93. https://doi.org/10.1080/09638288.2016.1277397.

24. Guo R, Berkshire SD, Fulton LV, Hermanson PM. Predicting intention to use evidence-based management among US healthcare administrators: application of the theory of planned behavior and structural equation modeling. Int J Healthc Manag. 2019;12(1):25-32. https://doi.org/10.1080/2 0479700.2017 .1336856

25. Scott Barss K. Spiritual care in holistic nursing education: a spirituality and health elective rooted in TRUST and contemplative education. J Holist Nurs. 2020;38(1):122-30. https://doi.org/10.1177/0898010119889703.

26. Phillips EM, McGlynn SM, Topor DR, Stauffer CM. Training physician assistant students to provide evidence-based, holistic, patient-driven care: a novel curriculum. Med Sci Educ. 2021;31:319-23.

27. Theodoulou I, Sideris M, Lawal K, Nicolaides M, Dedeilia A, Emin El, et al. Retrospective qualitative study evaluating the application of IG4 curriculum: an adaptable concept for holistic surgical education. BMJ Open. 2020;10(2): e033181. https://doi.org/10.1136/bmjopen-2019-033181.

28. Dillman DA. Mail and internet surveys: the tailored design method. 2nd ed. New York: Wiley; 2020

29. Pong HK. The cultivation of university students' spiritual wellbeing in holistic education: longitudinal mixed-methods study. Int J Child Spirit. 2021:1-34. https://doi.org/10.1080/1364436X.2021.1898344.

30. Ottenhoff-de Jonge MW, van der Hoeven I, Gesundheit N, van der Rijst RM, Kramer AW. Medical educators' beliefs about teaching, learning, and knowledge: development of a new framework. BMC Med Educ. 2021;21:113.

\section{Publisher's Note}

Springer Nature remains neutral with regard to jurisdictional claims in published maps and institutional affiliations.

Ready to submit your research? Choose BMC and benefit from:

- fast, convenient online submission

- thorough peer review by experienced researchers in your field

- rapid publication on acceptance

- support for research data, including large and complex data types

- gold Open Access which fosters wider collaboration and increased citations

- maximum visibility for your research: over $100 \mathrm{M}$ website views per year

At $\mathrm{BMC}$, research is always in progress.

Learn more biomedcentral.com/submissions 